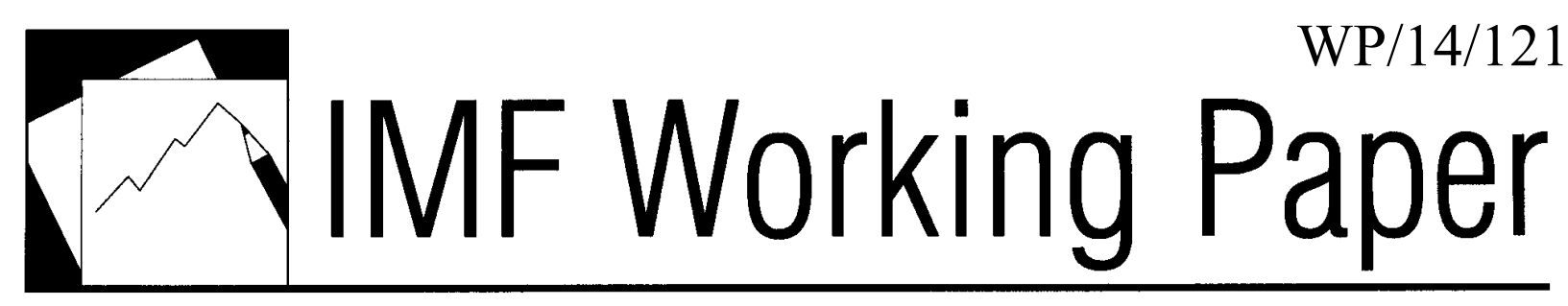

\title{
Modeling Appropriate Fiscal Targets and Optimal Consolidation Paths for Resource-Rich Countries: The Case of Suriname
}

\author{
Daniel Kanda and Mario Mansilla
}




\title{
IMF Working Paper
}

Western Hemisphere Department

\section{Modeling Appropriate Fiscal Targets and Optimal Consolidation Paths for Resource-Rich Countries: The Case of Suriname}

\section{Prepared by Daniel Kanda and Mario Mansilla}

Authorized for distribution by Jan Kees Martijn

July 2014

\section{This Working Paper should not be reported as representing the views of the IMF.}

The views expressed in this Working Paper are those of the author(s) and do not necessarily represent those of the IMF or IMF policy. Working Papers describe research in progress by the author(s) and are published to elicit comments and to further debate.

\begin{abstract}
This paper first attempts to quantify the natural resource wealth of Suriname from the perspective of its impact on the fiscal position, and then assesses the fiscal sustainability gap in that context. It then presents models to address the question of the optimal path of fiscal consolidation given the outlook for natural resource wealth, macroeconomic conditions, and country authority preferences.
\end{abstract}

JEL Classification Numbers: E62, H68, Q32

Keywords: Suriname; Natural Resource Wealth; Optimal Fiscal Consolidation; Fiscal Sustainability; Fiscal Targets

Authors’ E-Mail Address: dkanda@,imf.org; mmansilla@,imf.org 


\section{BACKGROUND}

The decade up to 2011 was characterized by a strong and prolonged rise in most commodity prices, interrupted only briefly by the onset of the global economic crisis in 2008-09. The increase was most pronounced for gold and copper prices, which in 2011 were more than five times higher than in 2001. However other commodities were not far behind: over the same period, petroleum prices and the overall index for metals more than quadrupled. Food prices also more than doubled. One commodity that did not share in the boom was aluminum where prices in 2011 were only about 66 percent higher than in 2001. Since 2011, however, commodity prices appear to have peaked, and recent movements have been downward, suggesting that commodity prices are likely to decline or remain flat at best over the medium term. Recent data from commodity futures markets and the expected slowdown in the pace of growth of the Chinese economy are also consistent with this outlook.

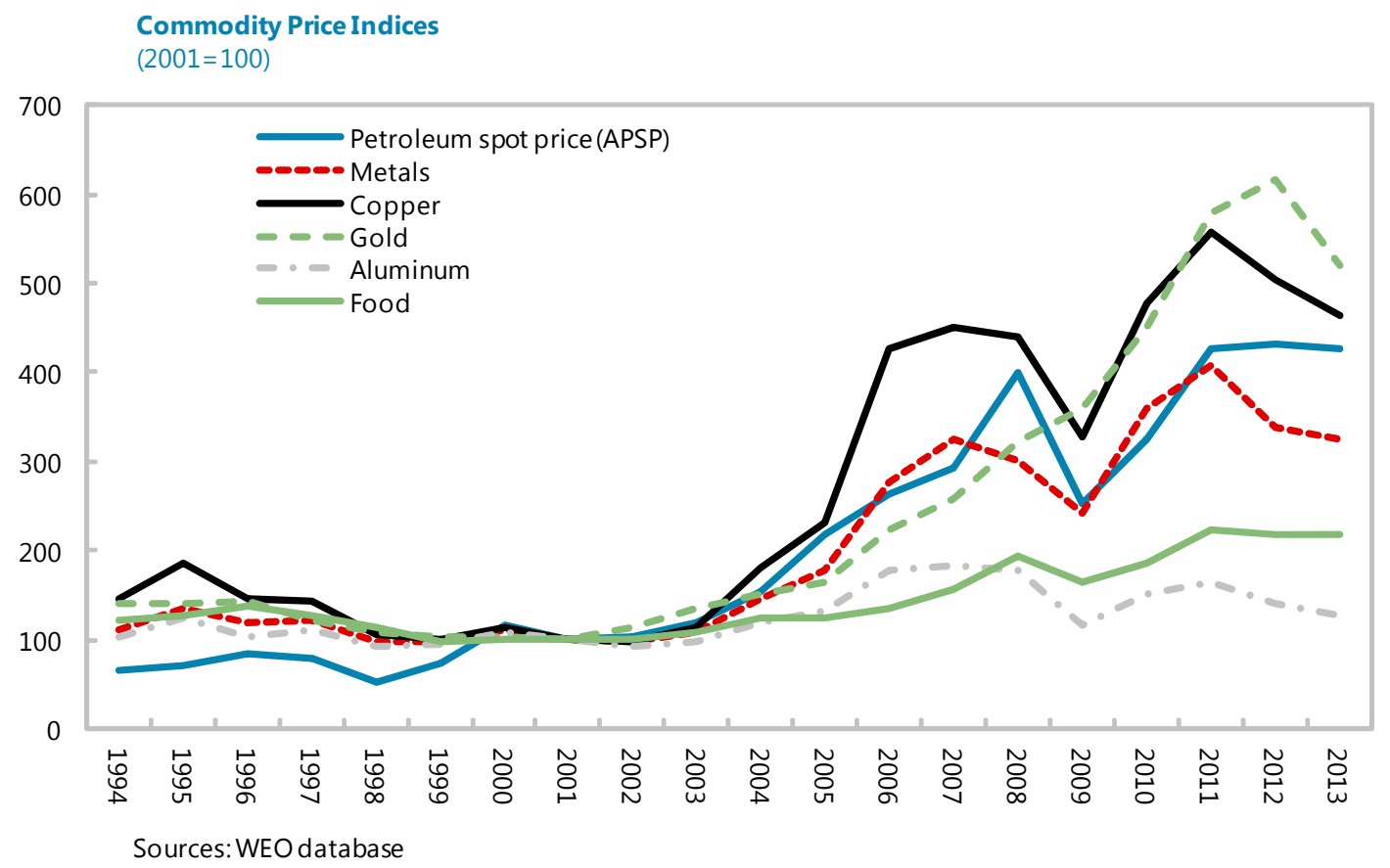

The commodity boom supported strong growth in commodity exporting countries, with rising consumption and investment. Moreover, high and rising commodity prices, coupled with strong economic growth, helped boost fiscal revenues. While some countries with stronger institutional and macro policy frameworks used this windfall to strengthen their fiscal positions, many commodity exporters have been notoriously prone to procyclical fiscal policies, and largely used the windfall to finance additional public spending. With the outlook now indicating flat or declining commodity prices, the windfall is set to decline or reverse, raising concerns about the implications for their fiscal and macroeconomic stability over the medium term. And the need for fiscal consolidation is coming into sharp focus in a number of resource rich countries. 
These developments highlight again the benefits and risks associated with natural resource wealth. Although such wealth creates opportunity to accelerate a country's development, it also comes with risks such as susceptibility to fluctuations in commodity prices which can be large and persistent, exhaustibility of natural resource deposits, a tendency to pro-cyclical fiscal policies that can amplify business cycles, and Dutch disease. Avoiding the impact of these risks on the fiscal position often requires the institution of a fiscal anchor or rule that enforces a sustainable fiscal position and countercyclical fiscal policy. The targets embedded in such an anchor should be based on a comprehensive assessment of fiscal sustainability, taking mineral wealth into account, together with a clear view of the size and timing of measures to be taken to move the fiscal position toward sustainability. This then enables a country to sustainably make use of mineral bounty to support development while also building up buffers to support countercyclical policy and to extend the benefits of exhaustible resources to future generations.

This paper studies these issues with a special focus on the case of Suriname which is highly exposed to commodity prices. Gold, oil, and aluminum make up more than 90 percent of exports, and mineral revenues exceed 40 percent of central government revenue. Moreover, a large fiscal adjustment need developed over 2012-13 as oil and gold prices began to decline. We first attempt to quantify the natural resource wealth of Suriname from the perspective of its impact on the fiscal position, and estimate the fiscal sustainability gap given the size of mineral wealth and the current fiscal position. We then present models to address the question of the optimal path of fiscal consolidation given the outlook for natural resource wealth, macroeconomic conditions, and country authority preferences on balancing the output and sustainability gaps. We find that under a conservative valuation of mineral wealth, Suriname has a large fiscal sustainability gap that requires substantial and frontloaded fiscal consolidation.

\section{A. Mineral Resources of Suriname}

Oil is the largest mineral contributor to fiscal revenues. The country has a near balance in terms of its fuel imports and exports. However Staatsolie, the national oil company, has fairly competitive production costs and therefore is a key contributor to central government revenues both in the form of dividends and taxes. Indeed, oil revenues comprised 29 percent of fiscal revenues in 2012. Proven oil reserves were estimated at 78.8 million barrels in mid2012, which at current extraction rates should last for 13 years approximately, but it is estimated that recent discoveries have extended this horizon by two additional years. Staatsolie is conducting intense exploration work off shore, both on its own account or through exploration contracts, and the geological conditions of its coastal territory indicate good chances of new findings.

Gold provides two thirds of exports, and its share of government revenue has also grown significantly to 13 percent currently. This has been enabled by the fact that the largest mine, Rosebel, increased its production substantially at the same time as international gold prices reached historically high levels. While there is significant small scale gold mining as well, it 
remains largely informal and very lightly taxed. ${ }^{1}$ The gold deposits in Suriname are part of the Guianas Shield which stretches between the Amazonas river in Brazil and the Orinoco river in Venezuela, so reserves appear substantial, only limited by their technical and economic viability. Apart from the Rosebel mine, which has now reached geological formations that are more expensive to mine, there are currently two projects that jointly could in principle double the volumes of production in the next five years or so. One of those projects is sponsored by Iamgold, the owner of Rosebel, and the other by a joint venture between Newmont and Suralco. The viability of those two projects depends critically on the evolution of the international price for gold, which at present appears to have passed its peak.

Bauxite used to be by far the most important natural resource for Suriname, but its importance has declined significantly. Around the time of World War II Suriname was a leading bauxite exporter in the world, producing about 25 percent of the total global production. However, over the following decades, changes in the international market, mainly related to significant increases of supply from other competitor countries and recent low international prices, have led Suriname to lose its market share (currently estimated at less than three percent), and therefore to a diminished relevance of the commodity in the domestic economy as well as for fiscal purposes. It currently accounts for less than 2 percent of fiscal revenues.

\section{ESTIMATING THE MINERAL WEALTH OF SURINAME}

Estimates of the mineral wealth of a country are inherently subject to large margins of error. In general, total mineral deposits are unknown, and the value of the deposits depends on a volatile long run price outlook. This uncertainty increases the difficulty of maintaining prudent countercyclical policies when commodity prices rise. It is common to have country authorities assuming overoptimistically that upswings in commodity prices are permanent, which leads to procyclical spending initiatives that often have to be scaled back significantly when the upswing ends. Moreover, turning points in the commodity price cycle are notoriously difficult to predict, exposing many commodity exporters to destabilizing boombust cycles.

A prudent approach to estimating mineral wealth for budget purposes would be based on conservative projections of long run price movements and mineral deposits. Thus, in general, price projections that are persistently well above the historical long run average should be avoided, unless there is a well founded and generally acceptable rationale for doing otherwise. Also, estimates of mineral deposits should be largely based on proven reserves, with probable or possible reserves being given a much lower weight in the estimation. Such an approach minimizes the possibility of over exuberant spending and boom bust cycles, and

\footnotetext{
${ }^{1}$ Informal gold mining is, however, an important source of employment and income in rural areas. Given its limited fiscal impact for the purposes of this paper, the focus is on the formal mining sector.
} 
is conducive to fostering the efficient use of fiscal resources. Moreover, if the mineral wealth turns out to have been underestimated ex post, the result is a stronger fiscal position and an accumulation of buffers that further strengthens macroeconomic stability.

For Suriname, the key assumptions underpinning the estimate of mineral wealth are as follows:

- Gold prices follow WEO projections up to 2018, and from then on the price falls gradually at five percent per year until it reaches a level of US\$500/ounce, a level consistent with the observed long run average price since 1903.

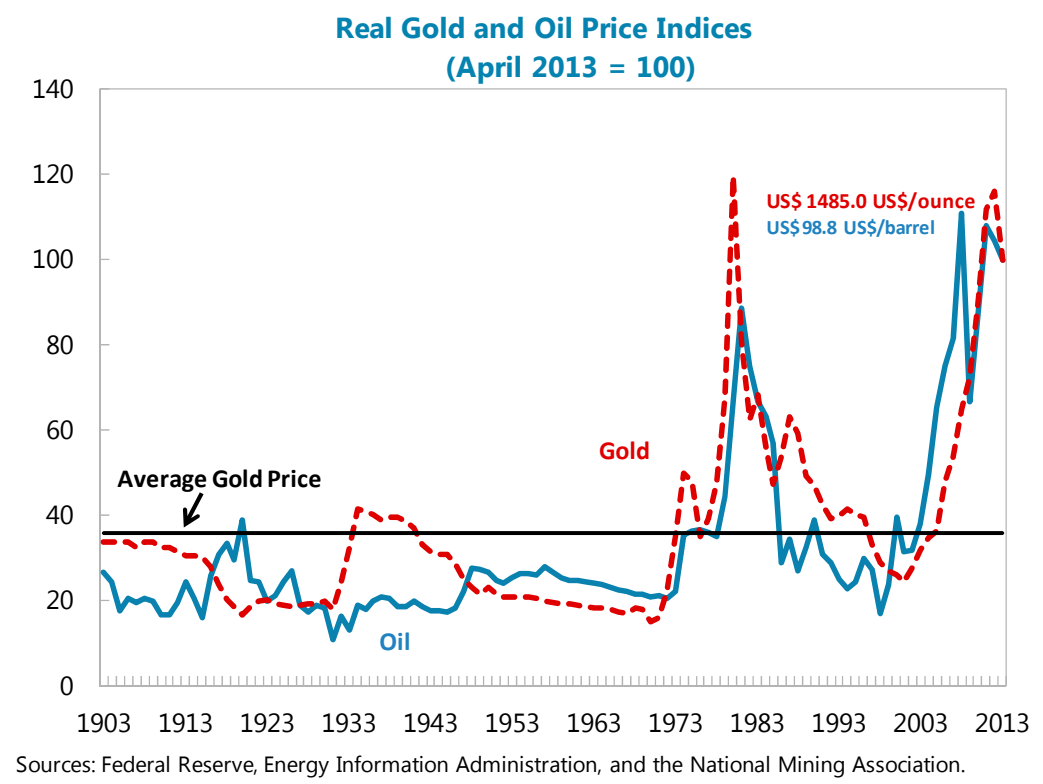

- It is assumed the gold mines will be commercially exploitable for up to 20 years provided the international price is above US $\$ 800$ which is estimated to be the break even cost for the mines operating in Suriname. Below that price level production would drop rapidly to zero.

- Fiscal income from informal gold mining (currently small) is not included in the estimation.

- Oil prices are also assumed to follow WEO projections until 2018, but given the additional value added of the extracted oil once the refinery starts operations, a premium of 18 percent is added from 2015 onward. After 2018, prices are assumed to increase by 1.5 percent per year until they reach 150 dollars per barrel (projected by the U.S. Energy Information Administration to be the long term price). ${ }^{2}$

\footnotetext{
${ }^{2}$ U.S. Energy Information Administration. Annual Energy Outlook 2012, Early Release. 2012. www.eia.gov
} 
- Proven reserves of oil are assumed to last for 15 years at the projected levels of production in 2018 and no significant discovery is assumed to take place in the period. The production decline is assumed to be gradual and starts after year ten and continues until year twenty.

- Bauxite-related fiscal revenues have declined to low levels, and are not a key focus of the estimation of mineral wealth. In any case, bauxite prices are assumed to follow WEO projections until 2018, with volumes similar to current levels. Beyond that, it is assumed that revenues from bauxite as a share of GDP stay at 2018 levels up to 2032 and then taper off to zero by 2050 .

- Government tax rates are assumed constant at the 2012 level.
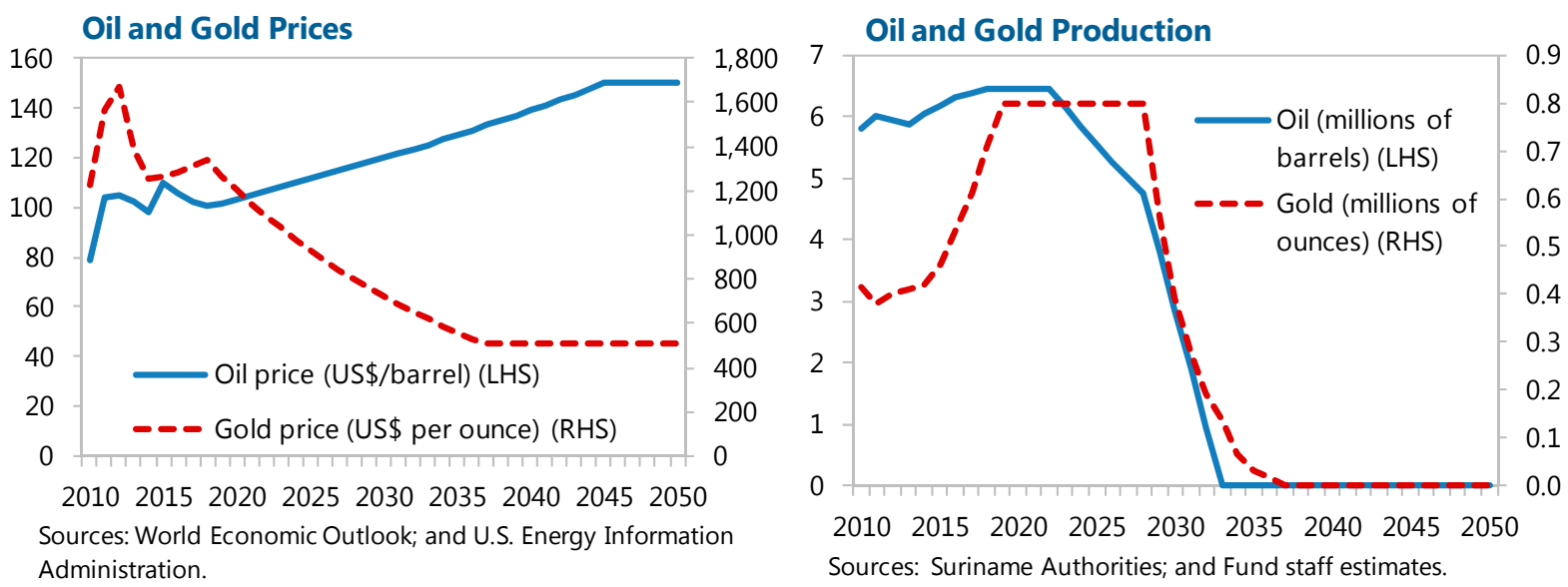

Under those parameters the value of the mineral resources for the central government is calculated as the discounted value of future revenue flows using a 4 percent real discount rate, which yields US\$ 5.5 billion, just above the current GDP.

\section{Fiscally Sustainable Policies for Suriname}

We now examine two approaches to help guide the setting of fiscal targets in resource-rich economies, namely the permanent income hypothesis and the inter-temporal budget constraint method. Under the permanent income approach, fiscal authorities estimate the net present value of the natural resource wealth, determine the portion that can be disposed of per period, and design the fiscal policies that would be consistent with those flows. The intertemporal budget constraint method calculates the fiscal sustainability gap, which yields the fiscal target that is consistent with the inter-temporal budget constraint (taking the projected flow of mineral revenues and the timing of its exhaustibility into account), and thus can be maintained indefinitely without leading to a need for sudden sharp disruptive adjustments to fiscal policy. 


\section{A. The Permanent Income Hypothesis}

Under the strict definition of the permanent income rule the flows available for consumption should match the returns to the discounted value of the project's future flows, so that the capital is preserved forever. It is possible, however, to estimate alternative scenarios based on less stringent rules that aim at graduating the spending over a period of time that is long enough to permit a gradual transition to the time in which the natural resources will be depleted. Such rules would also allow the authorities to target sustainable levels of nonmineral fiscal balances.

Several options can be considered for the consumption of the estimated mineral wealth, consistent with long run sustainability. In the first instance, the passive scenario is where no action is taken in the near term, but the authorities are forced to take corrective action over the long run as mineral revenues dwindle to zero in about 20 years (i.e., the non-mineral deficit is forced to be near zero), or face the need for significantly increasing the public debt. Alternatively, other scenarios show that early fiscal tightening prolongs the time horizon for the consumption of wealth and mitigates the need for large abrupt tightening once mineral revenues run out. A fixed annual nominal consumption consistent with early tightening to a non-mineral deficit target of about 5 percent of GDP would enable the consumption of mineral revenues forever (permanent income hypothesis scenario). Tightening to a target of 6 percent of GDP would exhaust mineral wealth at around 2060, but at that point the annual nominal consumption of mineral revenue would be a small share of GDP, requiring only minor offsetting action. Lower consolidation efforts lead to progressively shorter life of mineral resources. Given the large gap between the fiscal outcome in 2012 (with a non-mineral deficit of 151/4 percent of GDP) and sustainable paths, early and substantial consolidation seems warranted.

\section{B. Inter-Temporal Budget Constraint ${ }^{3}$}

A more comprehensive method for evaluating the fiscal stance of a country is to assess fiscal sustainability based on the inter-temporal budget constraint. This approach poses the following question: if the authorities decide to take no further fiscal measures from now

\footnotetext{
${ }^{3}$ The methodology in the following sections is based on Kanda (2011) and IMF (2012).
} 
onward, can they maintain that posture over an infinite horizon? If they can do so, then the inter-temporal budget constraint is satisfied, and the fiscal position is considered sustainable (and the fiscal sustainability gap is then zero). However, in most countries this is not the case, and protracted inaction then typically leads to a situation where the debt-GDP ratio rises continuously without bound, with interest payments taking an ever increasing share of government expenditure. This crowds out non-interest spending and increases the difficulties associated with financing the debt until the government is forced to take drastic action to put the fiscal position on a path consistent with sustainability.

The measurement of sustainability gaps thus informs policymakers about the amount of measures needed to get to the point of sustainability. Indeed, reflecting these considerations, the European Commission (EC) has been at the forefront of pushing for the widespread calculation and use of fiscal sustainability gaps, and it is now customary for all EU countries to calculate fiscal sustainability gaps, in coordination with the EC, every few years. This comprehensive exercise takes into account all the major exogenous changes expected to affect the fiscal position over the long run, including the two most common - natural resource depletion and population aging.

Due to lack of data, the current exercise for Suriname excludes population aging. While Suriname's population is currently young, the old age dependency ratio has been creeping up, and with the planned institution of a nation-wide social safety net, aging pressures are likely to become increasingly significant over the long run. However, incorporating this would require long run projections of population aging and its impact on fiscal spending on pensions and health care which are currently not available. To the extent that aging pressures exist, this would require additional fiscal consolidation measures to maintain sustainability (i.e. the fiscal sustainability gap would be larger).

\section{Estimating the fiscal sustainability gap}

The starting point for this analysis is the equation defining the evolution of public debt:

$$
B_{t}=B_{t-1}(1+r)-P_{t-1}
$$

Where $B_{t}, r$, and $P_{t}$, represent the debt stock at the beginning of period $\mathrm{t}$, the discount rate, and the primary surplus in period t, respectively. Dividing equation (1) by nominal GDP gives the following equation:

$$
b_{t}=b_{t-1}\left(\frac{1+r}{1+g}\right)-p_{t-1}\left(\frac{1}{1+g}\right)
$$

Where $b_{t}$ and $p_{t}$ represent the debt to GDP ratio at the beginning of period $t$ and the primary surplus to GDP ratio in period $t$, respectively, and $g$ represents the growth rate of GDP, 
assumed to be constant for algebraic simplicity. Solving equation (2) forward and imposing the no-Ponzi-scheme condition yields the government inter-temporal budget constraint:

$$
b_{t}=\left(\frac{1}{1+r}\right) \sum_{j=0}^{\infty}\left(\frac{1+g}{1+r}\right)^{j} p_{t+j}
$$

Thus, essentially, for a government to satisfy its inter-temporal budget constraint it must run future primary surpluses of sufficient size in present value terms to pay off the initial stock of debt. This is required so that over the long run the government can meet all its obligations. Otherwise, at some point it will become clear that the government cannot meet all its obligations, which will prompt investors to refuse to buy its debt and thus force drastic changes to fiscal policy.

For any given current fiscal stance (i.e. the non-mineral structural primary fiscal balance) and given the outlook for growth and other expected exogenous changes such as population aging and evolution of natural resource revenues, a "passive" path for the primary balance over an infinite horizon can be estimated. For Suriname, the most substantial exogenous changes analyzed in this exercise are due to the evolution of natural resource wealth, which impacts the expected path for fiscal revenues and therefore the passive path for the primary balance. As noted above, we assume the absence of population aging. On that basis the sustainability gap in stock terms (which is the total inter-temporal debt in present value terms) is then given by:

$$
V_{t}=b_{t}-\left(\frac{1}{1+r}\right) \sum_{j=0}^{\infty}\left(\frac{1+g}{1+r}\right)^{j} p_{t+j}
$$

And the sustainability gap in flow terms - hereafter simply called the sustainability gapwhich is defined as the constant change to the primary balance in percent of GDP such that the sustainability gap in stock terms is zero is thus derived as:

$$
S_{t}=(r-g)\left[b_{t}-\left(\frac{1}{1+r}\right) \sum_{j=0}^{\infty}\left(\frac{1+g}{1+r}\right)^{j} p_{t+j}\right]
$$

As an operational matter, in using equation (5) to calculate the sustainability gap one has to also take into account the possibility of a non-zero output gap, since the passive path for the primary balance over the medium term is influenced also by the evolution of the output gap. For example, if the output gap is negative (positive), then even without measures one would expect the primary surplus to improve (worsen) as the output gap closes over the medium term, with the amount of improvement dependent on the sensitivity of the primary surplus to 
the output gap. We model this explicitly, using the following commonly used equation for estimating the structural primary balance:

$$
p_{t}^{*}=p_{t}-\partial O_{t}
$$

Where $\mathrm{O}_{t}, p_{t}^{*}$ and $\partial$ represent the output gap in percent of GDP in period $t$, the structural primary balance in percent of GDP in period $t$, and the elasticity of the primary balance with respect to the output gap, respectively. Substituting equation (6) into equation (5), we obtain:

$$
S_{t}=(r-g)\left[b_{t}-\left(\frac{1}{1+r}\right) \sum_{j=0}^{\infty}\left(\frac{1+g}{1+r}\right)^{j}\left(p_{t+j}^{*}+\partial O_{t+j}\right)\right]
$$

Another issue that arises operationally is how to calculate the infinite sum in the formula. Here, a common assumption, which we also use, is that at some point in the distant future a steady state is achieved, beyond which the primary balance in percent of GDP stays constant. This then means that the sum of terms from the time the steady state is achieved to infinity becomes that of a geometric progression with a finite sum. Assuming that the steady state is achieved in period $j=\tau$, then for the subsequent period $j=\tau+1, \ldots \ldots \infty$, we have $p_{t+j}^{*}=p_{\tau}$ and $O_{t+j}=0$, and can express equation (7) as follows:

$$
S_{t}=(r-g)\left[b_{t}-\left(\frac{1}{1+r}\right)\left\{\sum_{j=0}^{\tau}\left(\frac{1+g}{1+r}\right)^{j}\left(p_{t+j}^{*}+\partial O_{t+j}\right)+\left(\frac{1+g}{1+r}\right)^{\tau+1}\left(\frac{p_{\tau}}{r-g}\right)\right\}\right]
$$

Our estimate of Suriname's sustainability gap is about 14 percent of GDP. This large gap primarily reflects the outlook for mineral revenue, which is expected under the conservative baseline assumptions to decline from around 11 percent of GDP in 2012 to zero over the long run (thus requiring offsetting measures of similar magnitude to satisfy the inter-temporal budget constraint) and the large fiscal deficit (4 percent of GDP in 2012) which is adding to debt and will need to be offset by measures. ${ }^{4}$

In a scenario where no corrective measures are taken while mineral revenue is depleted, public debt would mathematically rise to over 700 percent of GDP by 2060 in view of the substantial sustainability gap. Alongside, the primary balance is projected to decline by $11 \frac{1}{2}$

\footnotetext{
${ }^{4}$ Using a somewhat less conservative assumption where the nominal mineral revenue projected for 2018 is maintained thereafter only slightly reduces the sustainability gap to $133 / 4$ percent of GDP, as that nominal value declines continuously as a share of GDP over the long run.
} 
percentage points to a deficit of $14 \frac{1}{2}$ percent of GDP, while the overall fiscal deficit deteriorates by over 74 percentage points to around 78 percent of GDP. The exploding debt stock causes interest payments to rise exponentially, consuming an ever-increasing share of fiscal expenditure. In practice, of course, investors would repudiate Suriname's debt long before debt rises to such levels, forcing abrupt fiscal tightening to restore sustainability. In contrast, at the opposite extreme, immediate full adjustment implies that gross debt is driven to zero by 2015 , with a substantial buildup of government assets thereafter to help offset the depletion of natural resource revenues.

\section{OPTIMAL FISCAL CONSOLIDATION PATHS}

The pace of consolidation will reflect the balancing of twin conflicting objectives of reducing both the output and the fiscal sustainability gaps. A model to assess the optimal pace of consolidation is constructed as follows: the authorities are assumed to care about both the sustainability and output gaps, and to prefer that both be zero. However, these objectives are conflicting, in that action to close the sustainability gap (fiscal tightening) comes at the expense of widening the output gap in a negative direction, while on the other hand, action to close the output gap (fiscal loosening) increases the sustainability gap. Thus, over an infinite horizon, the authorities' problem can be characterized as choosing a path for the fiscal stance that minimizes the following quadratic objective function.

$$
\sum_{t=0}^{\infty} \beta^{t}\left(\alpha \mathrm{O}_{t}^{2}+(1-\alpha) S_{t}^{2}\right)
$$

Where $\mathrm{O}_{t}, \alpha,(1-\alpha)$, and $\beta$, represent the output gap in percent of GDP in period $t$, the weight placed by the authorities on closing the output gap, the weight placed by the authorities on closing the sustainability gap, and the authorities' rate of time preference, respectively, with $\beta=1 /(1+r)$.

The output gap is assumed to evolve according to the following equation:

$$
\mathrm{O}_{t}=\lambda \mathrm{O}_{t-1}-\xi\left(f_{t}-f_{t-1}\right)
$$

Where $f_{t}, \lambda$ and $\xi$, represent, respectively, discretionary fiscal measures taken (in percent of GDP) in period $t$, an autoregressive parameter on the output gap which determines how long it would take for the output gap to be eliminated through self-repair of the economy and other factors apart from fiscal action, and the fiscal multiplier.

It is necessary to adjust the sustainability gap formula to reflect discretionary actions. If we adjust equation (5) to take account of discretionary fiscal measures taken in time $t$, in addition to the "passive" evolution of the primary surplus, this yields: 


$$
S_{t}=(r-g)\left[b_{t}-\left(\frac{1}{1+r}\right) \sum_{j=0}^{\infty}\left(\frac{1+g}{1+r}\right)^{j} p_{t+j}-\left(\frac{1}{r-g}\right) f_{t}\right]
$$

And some algebraic manipulations reveal that the sustainability gap evolves as follows:

$$
S_{t}=\left(\frac{1+r}{1+g}\right) S_{t-1}-\left(f_{t}-f_{t-1}\right)
$$

Equation (12) confirms that in the normal case where the discount rate exceeds the GDP growth rate, delaying actions to ensure sustainability is costly. The magnitude of the sustainability gap increases over time absent discretionary consolidation measures, since the discount rate (which governs the pace of debt accumulation) exceeds the GDP growth rate (which governs the burden of debt relative to GDP).

The authorities' problem is to choose the size of fiscal measures in time $t$ to minimize the objective function (9) subject to equations (10) and (12). Given the quadratic preferences and linear constraints, we know that the policy function for this optimization problem is a linear function. We therefore speculate that the fiscal consolidation pace is governed by the following equation:

$$
f_{t}-f_{t-1}=A \mathrm{O}_{t-1}+B S_{t-1}
$$

Where $A>0$ and $B>0$. Substituting equation (13) into the first order condition of the authorities' problem, and solving for A and B yields:

$$
f_{t}-f_{t-1}=\left(\frac{\alpha \xi \lambda}{\alpha \xi^{2}+(1-\alpha)}\right) \mathrm{O}_{t-1}+\left(\frac{(1-\alpha)(1+r)}{\left(\alpha \xi^{2}+(1-\alpha)\right)(1+g)}\right) S_{t-1}
$$

Thus, the optimal path for fiscal consolidation depends on the initial values for the output and sustainability gaps, the fiscal multiplier, the speed of self-correction of output gaps, the discount and GDP growth rates, and the authorities' preferences.

\section{A. Calibration of the Model}

For Suriname, starting in year 2013, the initial sustainability gap as of 2012 is calculated above at 13.9 percent of GDP, while it is estimated that the (positive) output gap in 2012 was 0.5 percent of GDP. $\lambda$ is calibrated to equal 0.5 , implying that absent fiscal measures and ceteris paribus, an output gap of 2 percent of GDP is eliminated after six years via spillovers, confidence effects, monetary policy actions, self repair etc. The fiscal multiplier is taken to be relatively small at 0.5 , as Suriname is a small and very open economy. The nominal 
discount rate and long run average nominal GDP growth rate are taken to be 10 percent and $9 \frac{1}{4}$ percent respectively.

The authorities' preference weight parameter is determined based on "revealed preference." The approach is as follows: we take the value of $\alpha$, where $0 \leq \alpha \leq 1$, to be that which is consistent with the amount of fiscal tightening taken the last time there were similar circumstances with a large need for fiscal tightening (2011). In 2011, starting with an output gap of -0.5 percent and a sustainability gap of about 13 percent, the authorities implemented structural fiscal consolidation of 4 percent of GDP, which is consistent with a value of $\alpha$ of 0.89 , and this is the value we use in our exercise.

\section{B. Model Predictions}

In general, the optimal consolidation path requires significant front-loading of adjustment, but also envisages that full elimination of the sustainability gap takes place over a long horizon. Quadratic preferences mean that the pressure to act to reduce any of the two gaps under consideration increases in nonlinear fashion with the size of that gap. Thus, if the sustainability gap is large enough relative to the output gap, as is the case for Suriname, the optimal immediate fiscal tightening would be one that trades a substantial reduction in the sustainability gap for some negative movement in the output gap. Therefore (subject to the weights in the authorities' preferences) the larger the sustainability gap, the more optimal it is to front-load adjustment.

For Suriname, the model predicts an optimal path where there is fiscal tightening of about 5 percent of GDP in 2013, with the pace of adjustment tapering off significantly thereafter. This would have essentially fully offset the slippage of 2012. The initial impact of the fiscal tightening measures is however partly offset by the impact of the worsening output gap on revenues, and thus the headline overall balance is projected to only improve by about 3 percent of GDP in 2013, with the remaining improvement to the headline balance coming in later years as the output gap declines toward zero. Over the medium term (i.e. by 2018) the optimal structural fiscal adjustment effort totals 101/2 percent of GDP, which would offset a projected $3 \frac{1}{2}$ percent of GDP decline in mineral revenues over the period and improve the headline fiscal balance to a surplus of $2^{1 / 2}$ percent of GDP for 2018 . Alongside, the nonmineral deficit declines to 51/4 percent of GDP in 2018. Over the long run the sustainability gap declines steadily, though the pace of decline drops over time, and it is eliminated by 2043. Because of the delay in achieving sustainability, the total amount of measures needed rises slightly above the sustainability gap to $14 \frac{1}{2}$ percent of GDP.

\section{Sensitivity of Model Predictions}

Figure 2 presents a series of sensitivity tests that indicate how the optimal tightening predicted by the model for 2013 varies when initial conditions or parameter values are varied (bearing in mind that the optimal tightening for 2013 under the assumed parameter values and initial conditions is 5 percent of GDP). 
- $\quad$ Fiscal multiplier. The optimal tightening varies strongly with the change in the fiscal multiplier, particularly for values below one. Over the range considered (0-2), optimal tightening is highest with a zero multiplier (where immediate full closure of the sustainability cap is indicated given the absence of negative impact of tightening on the economy), and it declines in monotone but nonlinear fashion as the multiplier increases from zero. As the assumed value of the fiscal multiplier is at a point where the curve is still quite steep, it implies that the optimal tightening is rather sensitive to the value chosen. For example, if the multiplier were to be 0.7 rather than 0.5 , optimal tightening in 2013 would be $3 \frac{1}{4}$ percent of GDP rather than the 5 percent of GDP. On the other hand, with a multiplier of 0.3 the optimal tightening for 2013 would be $81 / 2$ percent of GDP.

- Country preferences. In common with most countries, the preference parameter is tilted in favor of closing the output gap rather than the sustainability gap, with a value of 0.89 . This is because output gaps typically have more immediate social and political implications than sustainability gaps, whose effects generally manifest over the long run. In the neighborhood of the chosen parameter value, the curve is quite steep, indicating that the optimal tightening is sensitive to preferences. Moreover, beyond the value of 0.9 the sensitivity intensifies, so a slightly less hawkish preference would give rise to a significantly lower tightening for 2013. For example, with alpha at a value of 0.93 , the optimal tightening for 2013 would be $3 \frac{1}{2}$ percent of GDP.

- $\quad$ Resilience of the economy. The flexibility and resilience of the economy is reflected in the amount of time it takes to return to potential following a shock, absent discretionary fiscal measures. The more resilient the economy, the shorter the recovery time. We model this by varying the autoregressive parameter on the output gap (lambda) between zero and one, with a value of zero indicating instant adjustment to shocks. The result indicates that the optimal tightening for 2013 is not very sensitive to this parameter, with a variation of about $3 / 4$ percent of GDP across the range of this parameter.

- Initial output gap. Given well known difficulties in estimating output gaps in real time, current estimates could undergo substantial revisions in future. If it turns out that the output gap is more negative than current estimates, then it would have been optimal to consolidate less. However, it turns out that optimal tightening is only moderately sensitive to changes to the output gap - for example if the initial output gap were -0.5 percent instead of the assumed 0.5 percent, the optimal tightening for 2013 would decline to $4 \frac{1}{2}$ percent of GDP.

- Initial sustainability gap. By its very nature the sustainability gap estimate is with a significant margin of uncertainty, as it involves long run projections. Thus it is important to examine how sensitive the optimal path would be to revisions in the 
estimate of the initial sustainability gap. Here we find moderate sensitivity, with a near-linear curve that is flatter than the 45 degree line. For example, if the initial sustainability gap were to be 10 percent of GDP rather than the estimated 14 percent, the optimal tightening for 2013 would be $3 \frac{3}{4}$ percent of GDP rather than 5 percent of GDP.

- Interest rate and GDP growth rate. As indicated in the Figure 2, these long run parameters have only a modest impact on the optimal tightening for 2013. 
Figure 1. Suriname: Fiscal Sustainability, 2012-60

(Percent of GDP)
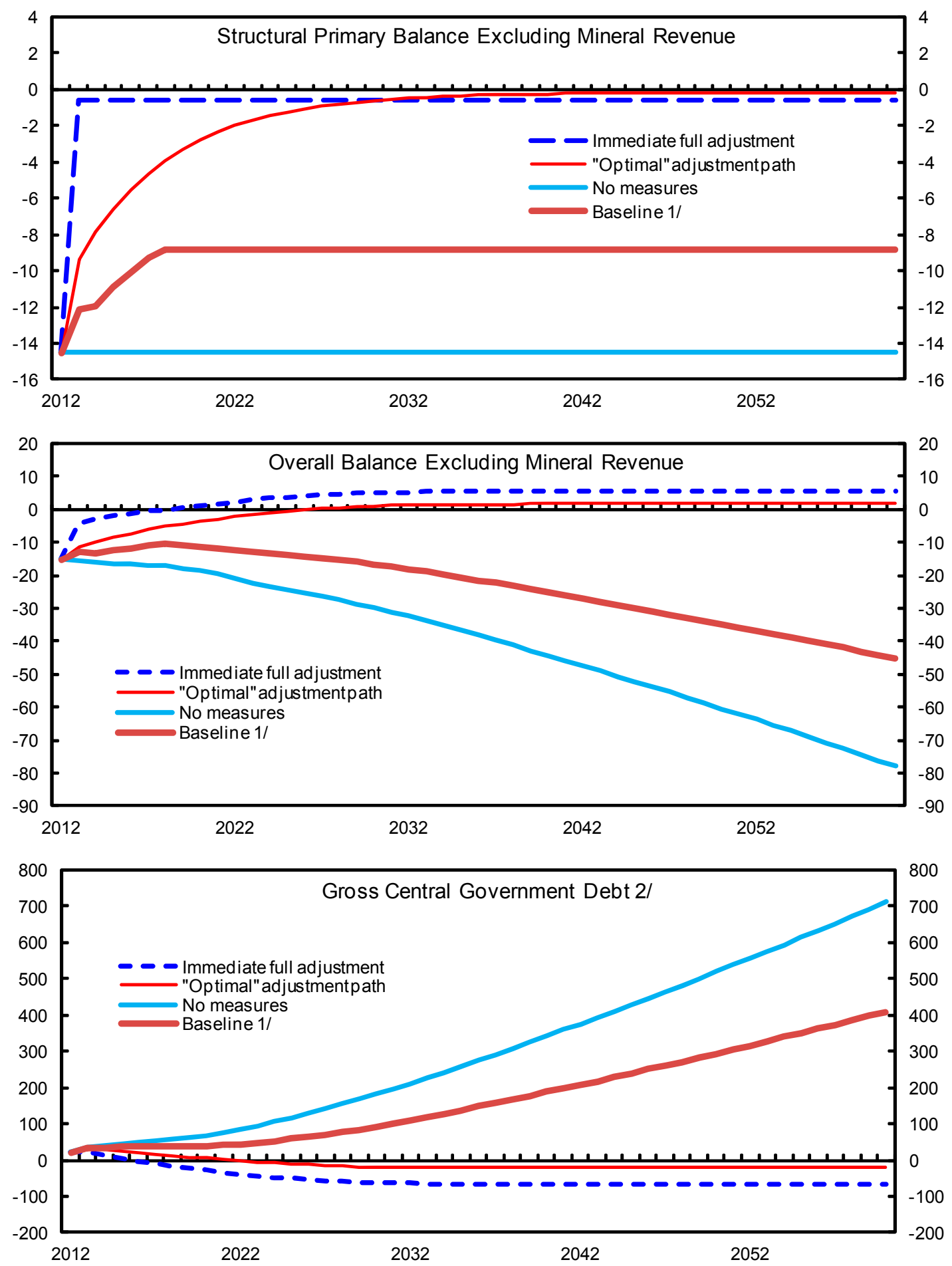

Sources: Authorities data, and Staff calculations.

1/ Baseline incorporates staff medium term baseline projections up to 2018, and assumes no further fiscal adjustment thereafter.

2/ Negative debt reflects the accumulation of assets 
Figure 1 (contd). Suriname: Fiscal Sustainability, 2012-60

(Percent of GDP)
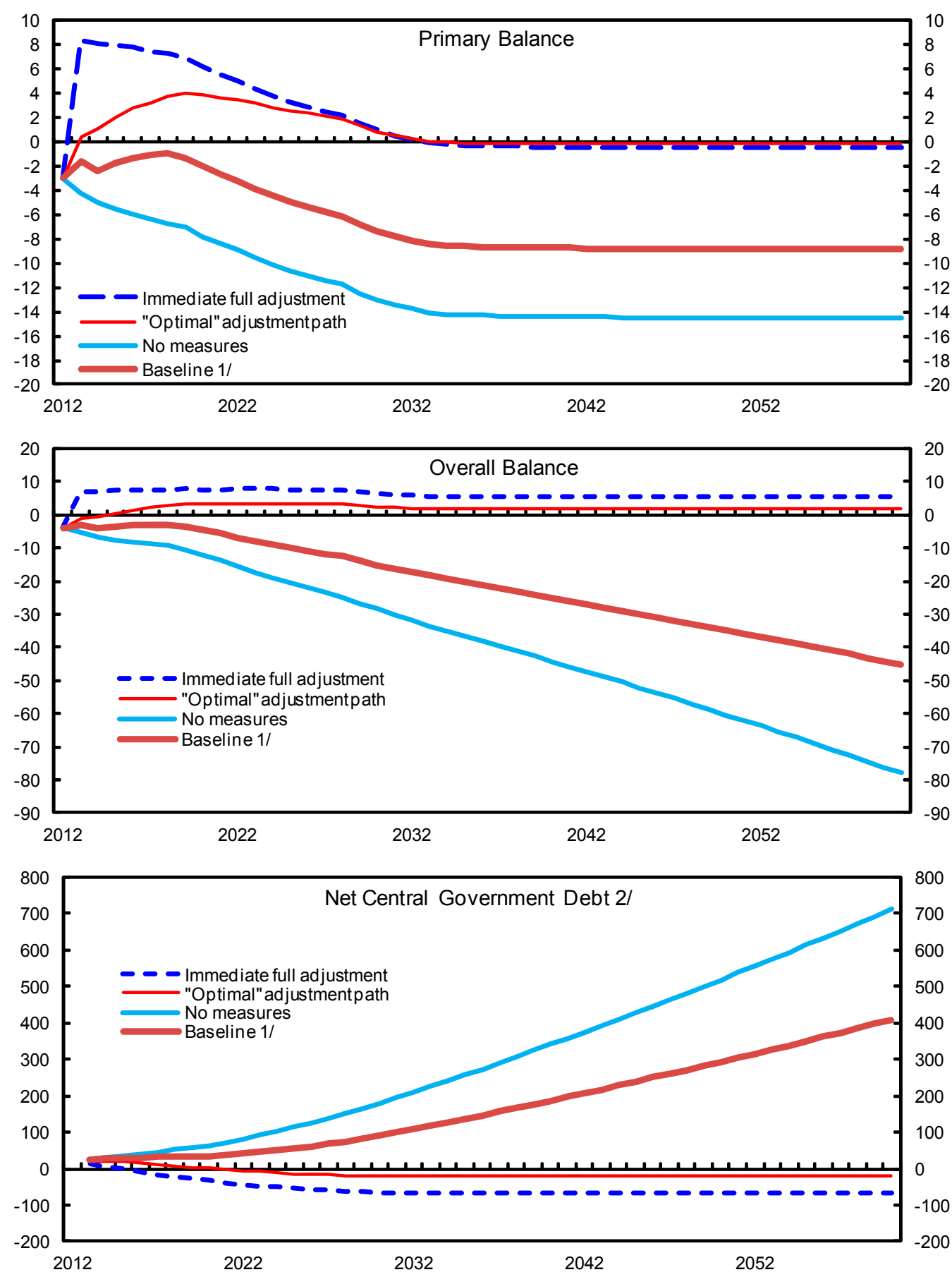

Sources: Authorities data, and Staff calculations.

1/ Baseline incorporates staff medium term baseline projections up to 2018 , and assumes no further fiscal adjustment thereafter.

2/ Net debt is calculated as gross debt minus the liquid assets of central government in the initial period (2013), estimated as the sum of US $\$ 20$ million set aside for initial deposit into the Sovereign Wealth Fund and US $\$ 375$ million of funds borrowed for use in purchasing equity stakes in two gold mining ventures. Negative debt reflects the accumulation of assets 
Figure 2. Suriname: Optimal Fiscal Tightening in 2013 Under Different Parameter Values and Initial Conditions (in percent of GDP) 1/

Fiscal Multiplier

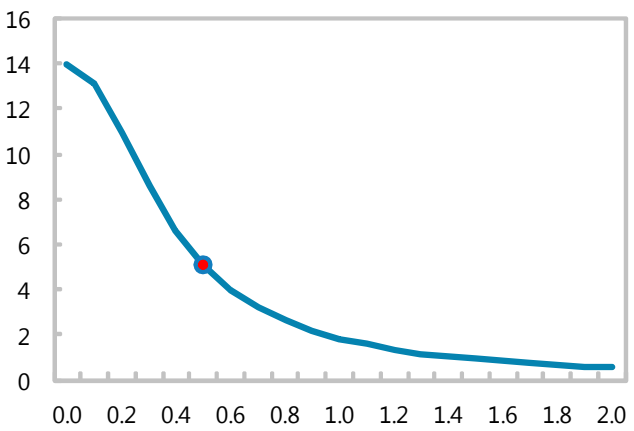

Initial Output Gap

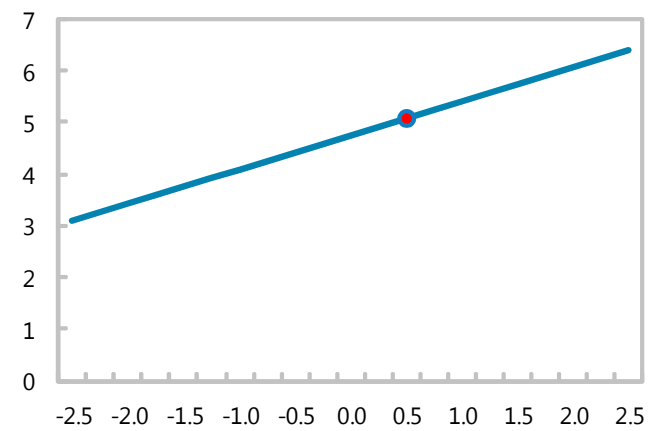

Initial Sustainability Gap

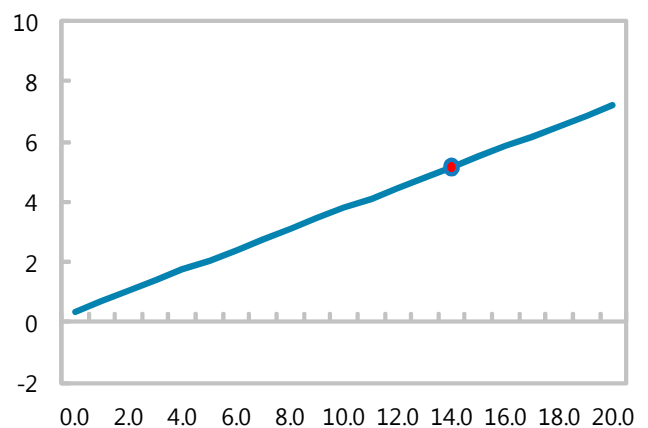

Preference Weight on Output Gap

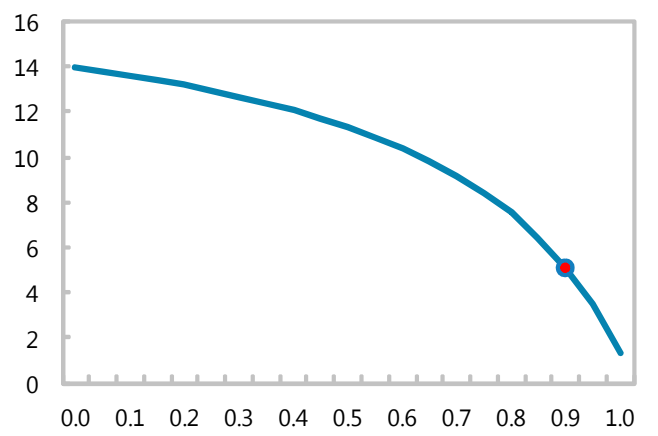

Autoregressive Parameter for Output gap

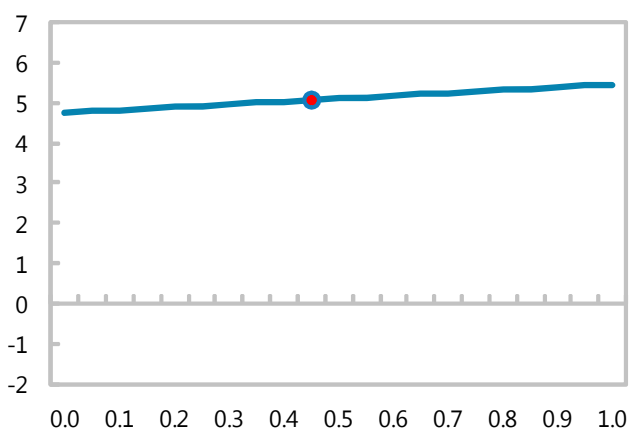

Discount Rate and GDP Growth Rate

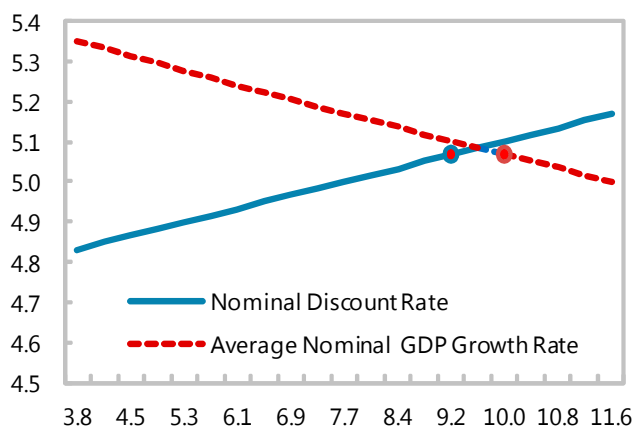

Source: Staff calculations based on model in IMF Working Paper WP/11/164.

1 / Baseline parameter values (with red dot) are: fiscal multiplier $=0.5$; preference weight $=0.89$; autoregressive parameter for output gap $=0.5$; discount rate $=10$ percent; GDP growth rate $=9.2$ percent. Baseline initial conditions are: initial output gap $=0.5$ percent; initial sustainability gap $=14.0$ percent of GDP. On this basis, the baseline optimal fiscal tightening for 2013 is 5.1 percent of GDP. 


\section{FinAl Remarks}

Both methodologies outlined above indicate a large fiscal adjustment need over the medium and long run. Indeed, the estimated sustainability gap of 14 percent is close to the gap observed as the size of the non-mineral deficit for 2012 which needs to be fully offset in some fashion as mineral revenues dwindle over time. The permanent income hypothesis approach outlined above however envisages a scenario where the bulk of adjustment is done in a single step, by choosing a fixed nominal amount of mineral revenues which should be consumed over the long run, whereas the optimal fiscal consolidation approach seeks to take into account the authorities' preferences and the costs of spreading out consolidation efforts over a long horizon. Overall, a medium term non-mineral fiscal deficit target in the neighborhood of 51/4 percent of GDP, while ambitious, appears appropriate given the size of the sustainability gap. The scale of required adjustment underscores the need for developing a sound fiscal framework to support consolidation efforts.

Given the uncertainties related to the estimation of mineral wealth, fiscal targets would need to be periodically updated. This would allow for appropriate changes to the fiscal target as the outlook for mineral wealth changes over time, but a conservative approach should be consistently used in such assessments to ensure the continued soundness of the fiscal position. 


\section{REFERENCES}

Fritz-Krockow, Bernhard, et.al., 2009, "Suriname: Toward Stability and Growth," International Monetary Fund, Western Hemisphere Department.

International Monetary Fund. 2012, “Macroeconomic Policy Frameworks for Resource-Rich Developing Countries". IMF Policy Paper.

Kanda, Daniel, 2011, "Modeling Optimal Fiscal Consolidation Paths in a Selection of European Countries”, IMF Working Paper No 11/164, 2011.

U.S. Energy Information Administration. Annual Energy Outlook 2012, Early Release. 2012. www.eia.gov. 